\title{
Electrodeposition of Fe-C Alloys from Citrate Baths: Structure, Mechanical Properties, and Thermal Stability
}

\author{
Timo Müller * (1) , Joseph Grimwood, Andrea Bachmaier ${ }^{(0)}$ and Reinhard Pippan \\ Erich Schmid Institute of Materials Science, Austrian Academy of Sciences, 8700 Leoben, Austria; \\ joseph.grimwood@cantab.net (J.G.); andrea.bachmaier@oeaw.ac.at (A.B.); reinhard.pippan@oeaw.ac.at (R.P.) \\ * Correspondence: timo.mueller@oeaw.ac.at; Tel.: +43-3842-804-228
}

Received: 13 April 2018; Accepted: 16 May 2018; Published: 17 May 2018

\begin{abstract}
A new citrate-based electrolyte is proposed for the electrodeposition of thick Fe-C films. The structure and properties of the deposits are compared to those from another electrolyte previously reported in the literature. Both consist of a nanocrystalline single-phase structure with a grain size of $20 \mathrm{~nm}$, which results in a hardness of up to $660 \mathrm{HV}$. Due to its higher growth rate, the new electrolyte is a promising candidate for the deposition of thick films. However, the codeposition of oxygen causes embrittlement, limiting the application of the deposits from both the new and the known electrolyte. On the other hand, the codeposited carbon and oxygen provide considerable thermal stability and even a hardening capacity upon annealing. The results are compared and discussed with respect to the previous investigations of electrodeposited Fe-C alloys.
\end{abstract}

Keywords: electrodeposition; iron-carbon; oxygen; nanocrystalline; mechanical properties

\section{Introduction}

The binary Fe-C system and carbon steels in general are among the most investigated materials since they are widely used for engineering applications and account for the lion's share of the global steel production. On the other hand, research on electrochemical deposition has grown rapidly during the last decades due to its industrial applications. Whereas electroplating of carbon steel parts with films made of other materials has been investigated in depth and is widely used in industrial applications, the use of Fe-C alloys as a coating material is rarely considered. The electrodeposition of $\mathrm{Fe}-\mathrm{C}$ alloys has been studied only in a very limited number of investigations and will be reviewed in the following.

The codeposition of carbon with iron was already reported in the 1950s by Petrov [1]. He observed 0.4-0.7 wt \% C in Fe deposits from a chloride bath containing glycerol and sugar, resulting in a high hardness of the deposits [1]. However, this phenomenon was not further investigated, until it was rediscovered by Izaki et al. in 1989 [2]. They found that the addition of citric acid and ascorbic acid to an iron sulfate bath enables the deposition of thick fine-grained layers incorporating about $1 \mathrm{wt} \% \mathrm{C}$ which results in a hardness of $800 \mathrm{HV}$ [2]. The deposits were shown to consist of a single-phase supersaturated solid solution with a body-centered tetragonal (bct) crystal structure and elongated grains of about $20 \mathrm{~nm}$ in width [3,4]. The carbon content-thus, hardness and tetragonal distortion - can be varied via the applied current density during deposition [4,5]. Upon annealing, decomposition of the supersaturated solid solution takes place via the formation of an intermediate carbide and cementite [5]. This decomposition is accompanied by a hardening effect up to $350{ }^{\circ} \mathrm{C}$ for deposits with high carbon contents [5]. These findings were confirmed by the work of Haseeb et al. [6] who investigated the decomposition upon annealing in more detail $[7,8]$. 
Oh et al. showed that pulse plating has only little effect on the structure and hardness of electrodeposited Fe-C alloys [9]. Nevertheless, ductility of the pulsed deposits is improved according to their findings investigating the surroundings of Vickers micro-indents [9].

Almost all studies on electrodeposition of Fe-C alloys use citric acid and/or ascorbic acid in the electrolyte in order to codeposit carbon. However, Fujiwara et al. showed that other hydroxycarboxylic and polycarboxylic acids are also suitable for the electrodeposition of Fe-C alloys [10,11]. Furthermore, they investigated the effect of other bath components [12].

Finally, the electrodeposition of ternary alloys including $\mathrm{Fe}-\mathrm{C}$ has been studied. However, these investigations are restricted to the addition of another element of the iron group (nickel [7] or cobalt [13]) and the elements phosphorous and boron $[14,15]$. The codeposition of hydrogen is inherent to the electrodeposition of iron and its alloys in general [16], but was shown to be significantly enhanced in the case of Fe-C alloy deposition [17]. Since the rate of hydrogen reduction is not only enhanced during the deposition of such carbon alloys, but also when they are used as electrodes for the hydrogen evolution reaction in an alkaline medium, they are promising candidates for the commercial production of hydrogen via this route [18].

In spite of these previous studies, many questions on the formation and properties of electrodeposited Fe-C alloys are still unsolved or even uninvestigated. For example, the exact mechanism of carbon co-deposition is still unclear, the distribution of carbon in the strongly supersaturated, nanostructured deposits have not been investigated and-despite the enormous hardness of the deposits-further investigations on the mechanical properties have been restricted to wear tests by Miyamoto et al. on Fe-C-P deposits [15]. In this work, a new citrate bath is proposed, aiming at the deposition of thick layers with high current densities in order to obtain nanocrystalline quasi-bulk Fe-C material via electrodeposition. The structure of the deposits is investigated both in the as-quenched and annealed state. Besides indentation, compression and bending tests are used to obtain further insights into the mechanical properties of these materials.

\section{Materials and Methods}

Electrodeposition was performed under constant current density using a computer-controlled IPS PGU10V-2A-OEM-MI potentiostat. A double-walled glass cell connected to a circulation thermostat was used to control the temperature during the experiments. The $\mathrm{pH}$ of the bath was measured before and after the experiment. Most samples were deposited under one of the following three conditions: from the new citrate bath at $65^{\circ} \mathrm{C}$ with $-50 \mathrm{~mA} / \mathrm{cm}^{2}$, from the same electrolyte at $50{ }^{\circ} \mathrm{C}$ with $-30 \mathrm{~mA} / \mathrm{cm}^{2}$ or from the electrolyte described by Haseeb et al. [8] at $50{ }^{\circ} \mathrm{C}$ and $-30 \mathrm{~mA} / \mathrm{cm}^{2}$. In the following, these deposition conditions are designated as A65, A50, and B50, respectively. The corresponding bath compositions and deposition parameters are shown in Table 1 . The new electrolyte contains sodium sulfate as a conducting salt and the small amount of citric acid in the bath from [8] is replaced by a larger amount of tri-sodium citrate. Thus, the $\mathrm{pH}$ is increased leading to the reduction of hydrogen codeposition on the one hand, but the presence of ferric hydroxides on the other hand. Furthermore, the higher concentration of citrate complexes lowers the effective bath changes due to incorporation of citrate molecules into the deposit. Whereas conditions A50 are used in order to see any effects of these bath composition changes on the structure of the deposit, the suitability of the bath for deposition under higher current densities is investigated with conditions A65, using a higher deposition temperature in order to increase the diffusivity of the species in the bath. Besides A65, A50, and B50, additional experiments under different conditions were performed in order to investigate the effect of certain deposition parameters and will be mentioned in the text. All experiments were performed without bath agitation. Polycrystalline copper plates were used as substrates. The substrates were aligned vertically in the bath and had a size of about $2 \mathrm{~mm}$ in thickness and $12 \mathrm{~mm}$ in diameter. A rod of ARMCO iron with a surface area of more than ten times the substrate area was used as soluble counter electrode. 
Table 1. Standard electrolytes and deposition parameters used in this study. Parameter sets A65 and A50 are new deposition conditions investigated in this work, whereas B50 is taken from [8].

\begin{tabular}{lccc}
\hline \multicolumn{1}{c}{ Sample Designation } & A65 & A50 & B50 \\
\hline Bath Composition (g/L) & \multicolumn{2}{c}{} \\
\hline Ferrous Sulfate Heptahydrate & \multicolumn{2}{c}{120} & 120 \\
Citric Acid & - & 1.2 \\
Tri-Sodium Citrate Dihydrate & \multicolumn{2}{c}{20} & - \\
L-Ascorbic Acid & \multicolumn{2}{c}{3} & 3 \\
Sodium Sulfate & \multicolumn{2}{c}{80} & - \\
\hline Deposition Parameters & \multicolumn{3}{c}{50} \\
\hline Temperature $\left({ }^{\circ} \mathrm{C}\right)$ & 65 & 50 \\
Current Density $\left(\mathrm{mA} / \mathrm{cm}^{2}\right)$ & -50 & -30 & -30 \\
pH (before deposition) & 4.2 & 4.2 & 2.5 \\
\hline
\end{tabular}

The structure of the deposits was characterized using a Zeiss LEO1525 scanning electron microscope (SEM) and a Philips CM 12 transmission electron microscope (TEM). X-ray diffraction (XRD) measurements of the as-deposited samples were performed in transmission with high-energy synchrotron radiation at the P07 HEMS beamline of PETRA III [19]. The photon energy for these experiments was $111 \mathrm{keV}$ and the beam size was $0.1 \times 0.5 \mathrm{~mm}^{2}$. Diffractograms of the annealed samples were recorded using a Rigaku SmartLab diffractometer with a $\mathrm{Cu}-\mathrm{K} \alpha$ source and a monochromator on the secondary side.

Vickers microhardness was measured on cross-sections of the deposits with a Buehler Micromet 5104 machine at a load of $500 \mathrm{~g}$ (HV0.5). For the nanoindentation experiments, which were also performed on cross-sections of the films, a Hysitron Triboscope with a diamond cube corner indenter was used. Compression and bending experiments were performed with a tension/compression module and a bending module of Kammrath \& Weiss, respectively. The compression samples were about $0.5 \mathrm{~mm}$ in the growth direction of the films and about $1.0 \mathrm{~mm}$ to $1.5 \mathrm{~mm}$ in the other two dimensions; the bending beams were $3 \mathrm{~mm}$ in width, $0.3 \mathrm{~mm}$ in height, and were tested in 3-point bending with a support span of $3.2 \mathrm{~mm}$. The samples for these experiments were prepared by mechanical grinding and polishing. The copper substrates were removed via grinding during the preparation of the compression and bending samples as well as before annealing to avoid crack formation due to the different thermal expansion coefficients of $\mathrm{Fe}-\mathrm{C}$ deposits and $\mathrm{Cu}$ substrates. Annealing was performed under a pressure of about $10^{-5} \mathrm{mbar}$ in a vacuum tube furnace.

\section{Results}

\subsection{Deposition Process}

Thick films with a smooth, black surface are obtained in a large range of bath compositions and deposition conditions. From a number of baths containing citric acid, tri-sodium citrate or mixtures of both, the two electrolytes shown in Table 1 provide the best results concerning the availability of thick, smooth deposits over a large current density range as well as concerning a high current efficiency. With these electrolytes, smooth films are obtained for current densities ranging from $-20 \mathrm{~mA} / \mathrm{cm}^{2}$ up to about $-50 \mathrm{~mA} / \mathrm{cm}^{2}$. For lower current densities, coarse grained deposits with a rough surface are formed with a very low current efficiency. The upper current density limit is caused by the formation of powdery deposits and can be shifted towards higher current densities by increasing the deposition temperature.

A cross-section of a typical deposit from this study is shown in Figure 1a. A homogeneous layer with smooth surface is obtained in the center of the substrate. Near the edge of the substrate, the layer thickness increases due to the edge effect, which also results in the growth of dendritic-like features directly at the edge of the samples. This structure can be maintained up to a thickness of more than 
$800 \mu \mathrm{m}$. However, if the deposition process is continued even longer, ceramic particles are included into the deposit resulting in a metallic matrix with ceramic second-phase particles (Figure 1b).

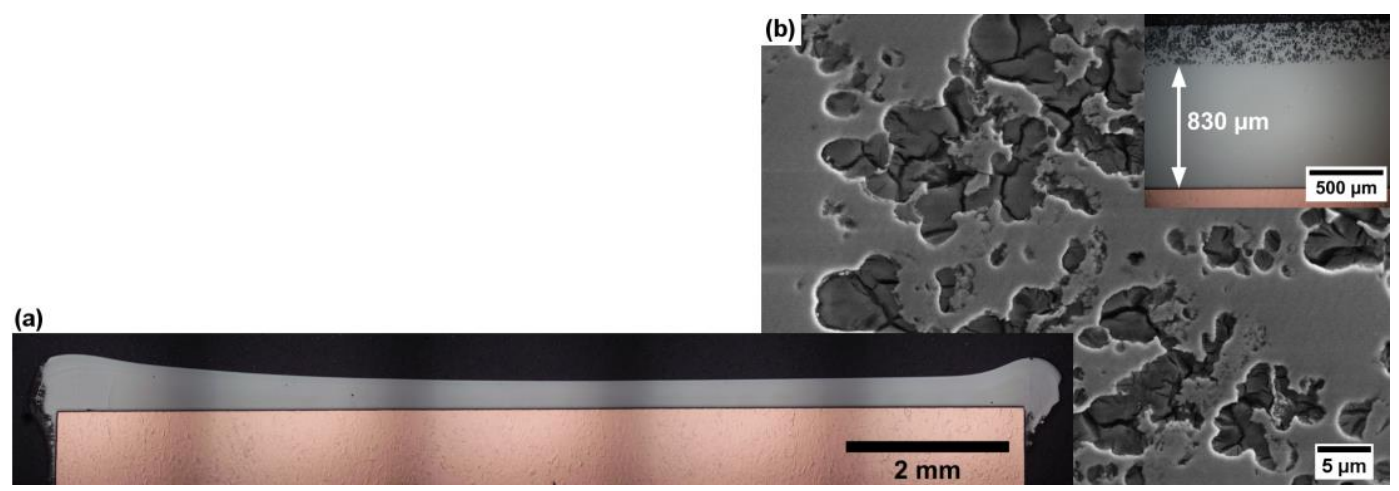

Figure 1. (a) Optical micrograph of a complete sample cross-section after deposition for $22 \mathrm{~h}$ under conditions B50; (b) scanning electron microscope (SEM) image of the sponge-like structure with ceramic inclusions formed at the top surface layer after prolonged deposition under conditions A65. The inlay shows a cross-section over the whole thickness of the sample.

The electrochemical potential directly after starting the deposition with respect to an $\mathrm{Ag} / \mathrm{AgCl}$ reference electrode is about $\mathrm{E}=-1100 \mathrm{mV}$ to $\mathrm{E}=-1150 \mathrm{mV}$ for conditions $\mathrm{A} 50$ and $\mathrm{A} 65$, whereas about $\mathrm{E}=-1200 \mathrm{mV}$ are obtained for B50. During deposition, the potential increases up to $\mathrm{E}=-1000 \mathrm{mV}$ to $\mathrm{E}=-1050 \mathrm{mV}$ for $\mathrm{A} 50$ and $\mathrm{A} 65$ and about $\mathrm{E}=-1100 \mathrm{mV}$ for B50 after $22 \mathrm{~h}$ of deposition. In the same time, the $\mathrm{pH}$ increases slightly to 4.3, 4.4, and 3.0 for A50, A65, and B50, respectively. For even longer deposition, the color of bath B50 changes from green to yellow after more than one day of deposition, indicating strong oxidation of the bath, i.e., formation of ferric ions. The potential change during the deposition process is a result of both the increasing surface area due to the edge effect (Figure 1a) and the bath changes during deposition, including the rise of $\mathrm{pH}$ due to hydrogen reduction, the reduction of the citrate concentration due to carbon codeposition (particularly for B50 due to the low concentration of citric acid), and concentration changes of ferrous ions due to unequal actual reaction rates at the working and counter electrode and due to oxidation to ferric ions.

The current efficiency calculated via Faraday's law from the mass of the deposits after $22 \mathrm{~h}$ deposition time scatters in the range of $70-90 \%$ for all three deposition conditions. Due to the pronounced edge effect, the current efficiency calculated from the film thickness near the center of the substrate is considerably lower, in the range of $40-50 \%$.

\subsection{As-Deposited State}

\subsubsection{Microstructure and Composition}

SEM shows the nanocrystalline nature of the Fe-C electrodeposits (Figure 2a). Needle-like grains elongated along the growth direction are observed throughout the deposits without any considerable changes over the film thickness. Even for the very thick films, in which the ceramic inclusions are observed (Figure 1b), the nanocrystalline structure of elongated grains is preserved, but their orientation becomes random. Only films, for which the deposition was stopped prior to the occurrence of ceramic inclusions, will be discussed in the following. The grains are about $20 \mathrm{~nm}$ in the short axis and have an aspect ratio of approximately two to three (Figure $2 b, c$ ).

Both TEM selected area diffraction patterns (not shown) and high-energy transmission XRD (Figure 3a) show that the deposits consist of a single phase of body-centered cubic structure. Only a tiny peak next to bcc (110) indicates the presence of another phase (Figure 3b). However, the phase could not be determined since only this single peak is visible. Due to the low intensity of the peak and the absence of further Bragg peaks, the amount of the phase is assumed to be very low $(<1 \%)$ 
and the films can be considered to be practically single-phase. A tetragonal distortion, as described for electrodeposited Fe-C alloys in the literature $[3,4,10,14,15]$ could not be found, but a tetragonal distortion with a small c/a ratio cannot be excluded due to the limited angular resolution of the diffraction data. The 2D diffraction patterns clearly reveal the preferred orientation of (211) planes perpendicular to the growth direction (Figure 3a). The presence of a (211) fiber texture without any preferred orientation within the plane parallel to the substrate was proven via a full texture measurement for a deposit from another citrate-based bath (not shown).

Analysis with a Leco CS-125 carbon analyzer revealed carbon contents of $1.0 \pm 0.1 \mathrm{wt} \%$ independent of the deposition conditions within the range of stable deposition of smooth deposits. Indications of significant amounts of oxygen were found using X-ray photoelectron spectroscopy, but no reliable quantitative amounts could be determined.
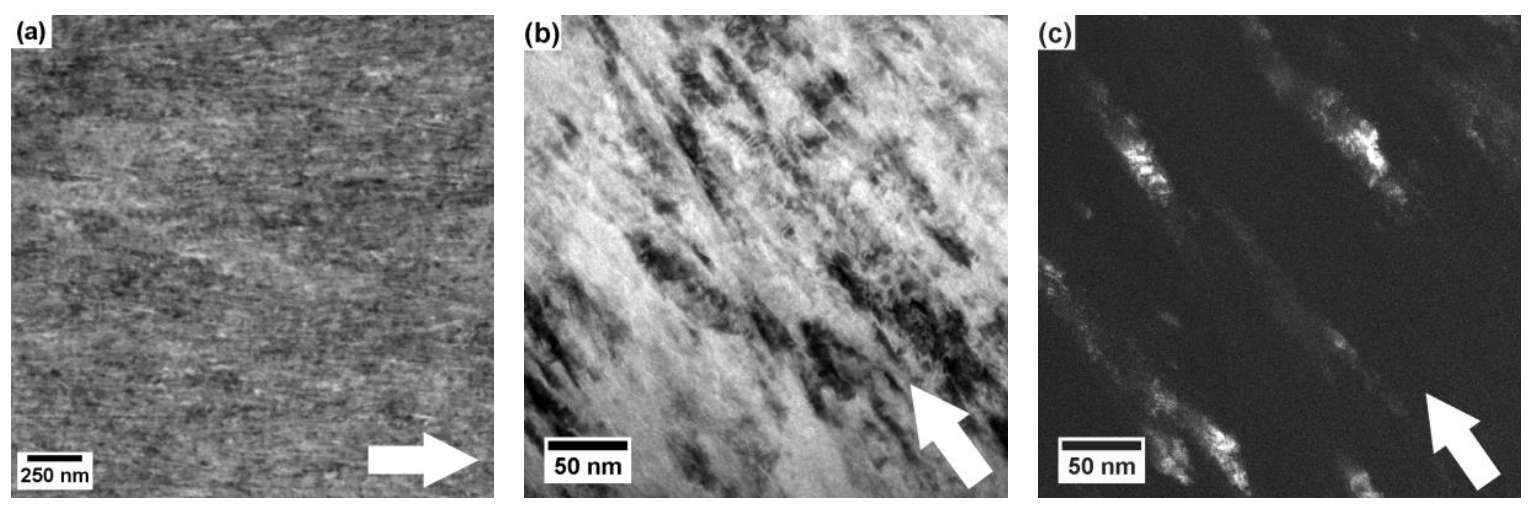

Figure 2. (a) Microstructure of an as-deposited A50 sample imaged with the backscatter-electron detector in the SEM; (b) Bright-field and (c) dark-field transmission electron microscope (TEM) images of an A65 sample in a film cross-section. The white arrows indicate the growth direction.
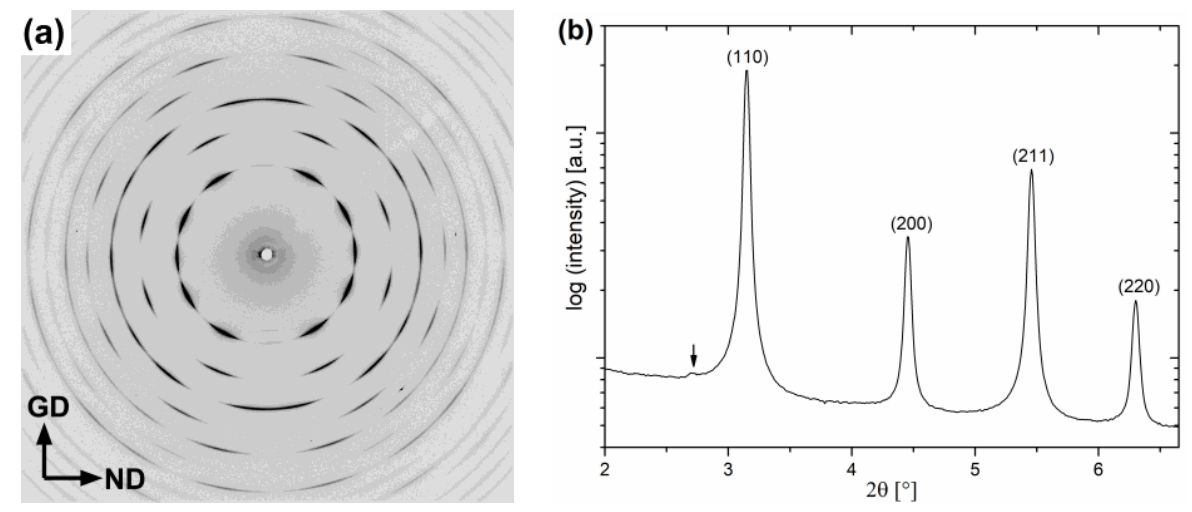

Figure 3. (a) High-energy X-ray diffraction (XRD) pattern of a B50 sample recorded with the primary beam in-plane. GD and ND indicate the growth direction and the in-plane direction, respectively; (b) Diffractogram obtained from (a) via integration over all azimuthal angles. The only indication of a small peak besides the ferritic phase is marked with an arrow.

\subsubsection{Mechanical Properties}

The microhardness equals $556 \pm 10 \mathrm{HV}$ for A50, $662 \pm 28 \mathrm{HV}$ for A65 and $660 \pm 17 \mathrm{HV}$ for B50. The hardness of deposits from other citrate and/or citric acid baths lies in between these values. The hardness slightly increases with increasing distance from the substrate. Vickers indents on film cross-sections, which are oriented with one diagonal parallel to the growth direction, show crack formation along this direction, whereas no cracks originating from the Vickers indents occur parallel to 
the substrate surface (Figure 4a). Using the equation by Niihara [20] for median cracks obtained from Vickers indentation, an estimated fracture toughness of $3.8 \mathrm{MPa} \mathrm{m}{ }^{0.5}$ is obtained from the measured crack lengths of both A50 and B50 samples, whereas for A65 $3.2 \mathrm{MPa} \mathrm{m}^{0.5}$ is determined.
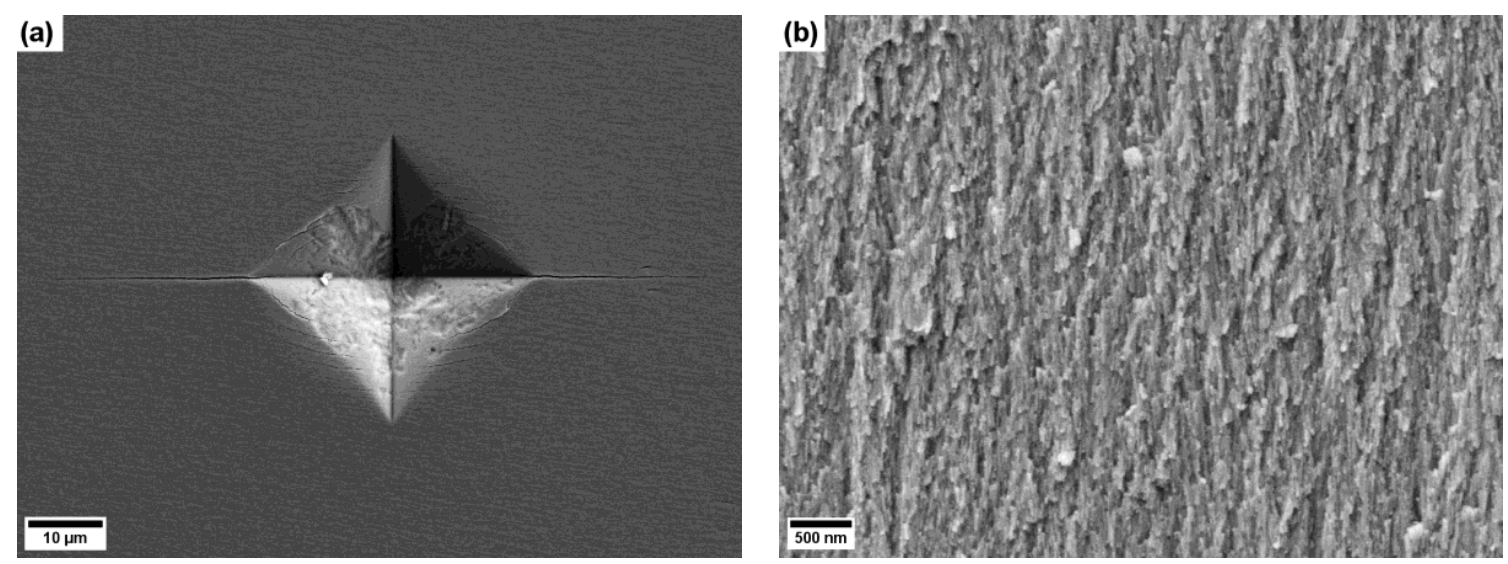

Figure 4. (a) SEM micrograph of a Vickers micro-indent on the cross-section of a B50 sample; (b) Exemplary fracture surface of an A65 sample after bending.

Both compression and bending tests reveal a completely brittle fracture behavior. Compression testing, which was performed on samples with the loading axis parallel to the growth direction as well as in normal orientation, results in catastrophic failure by a sudden mechanical collapse of the structure. The cuboidal bulk samples are transferred into many small powder-like particles of elongated shape indicating intercrystalline fracture. The maximum stress before failure scatters over a large range between $400 \mathrm{MPa}$ and $1800 \mathrm{MPa}$. Large scatter of the maximum stress is also observed in the bending experiments, but at a much lower level, between $100 \mathrm{MPa}$ and $190 \mathrm{MPa}$. In contrast to the compression samples, the bending beams break along one sharp interface, making the investigation of fracture surfaces feasible. Irregular morphologies varying from one sample to another are observed next to the surface of the bending beams which is under tension upon bending. Near the center, the fracture surface has the lowest roughness, but elongated features of similar size as the crystallographic grains can be found at higher magnifications in the SEM (Figure $4 \mathrm{~b}$ ). This structure becomes rougher, making an elongated structure even visible in the light microscope, when approaching the edge on the other side of the fracture surface which is mainly loaded with compressive stresses upon bending.

\subsection{Thermal Stability and Structure Evolution upon Annealing}

During isothermal annealing, the deposits from all three deposition conditions behave similarly. For this reason, the evolution upon annealing will be discussed in the following in a general way and conditions A50, A65, and B50 are only differentiated where necessary.

After annealing at $200{ }^{\circ} \mathrm{C}$ or $300^{\circ} \mathrm{C}$, no significant changes in the structure except a slight increase in contrast between the elongated grains can be observed in the SEM (Figure 5a,b). Neither are any changes in phase composition shown by XRD (Figure 6a). This corresponds well with a constant microhardness until $200{ }^{\circ} \mathrm{C}$ and only a slight increase at $300{ }^{\circ} \mathrm{C}$ (Figure $6 \mathrm{~b}$ ). On the contrary, isothermal annealing at $400{ }^{\circ} \mathrm{C}$ results in the formation of equi-axed precipitates with diameters ranging from a few nanometers up to about $70 \mathrm{~nm}$ (Figure 5c). Closer investigation of the regions between these precipitates proves the conservation of the elongated grain shape, although some grain growth occurs. The precipitation results in additional peaks in the XRD patterns, which are identified as cementite and magnetite (Figure 6a). The hardness is considerably increased to more than $800 \mathrm{HV}$ (Figure 6b). Increasing the annealing temperature to $500{ }^{\circ} \mathrm{C}$, the aligned orientation of the microstructure along the growth direction is lost and an isotropic structure exists throughout the film (Figure 5d). The structure is considerably coarsened as compared to the $400{ }^{\circ} \mathrm{C}$ annealed material. This coarsening results in a 
drop of the microhardness below that of the as-deposited state (Figure 6b). XRD indicates no significant changes as compared to $400^{\circ} \mathrm{C}$ (Figure 6a).
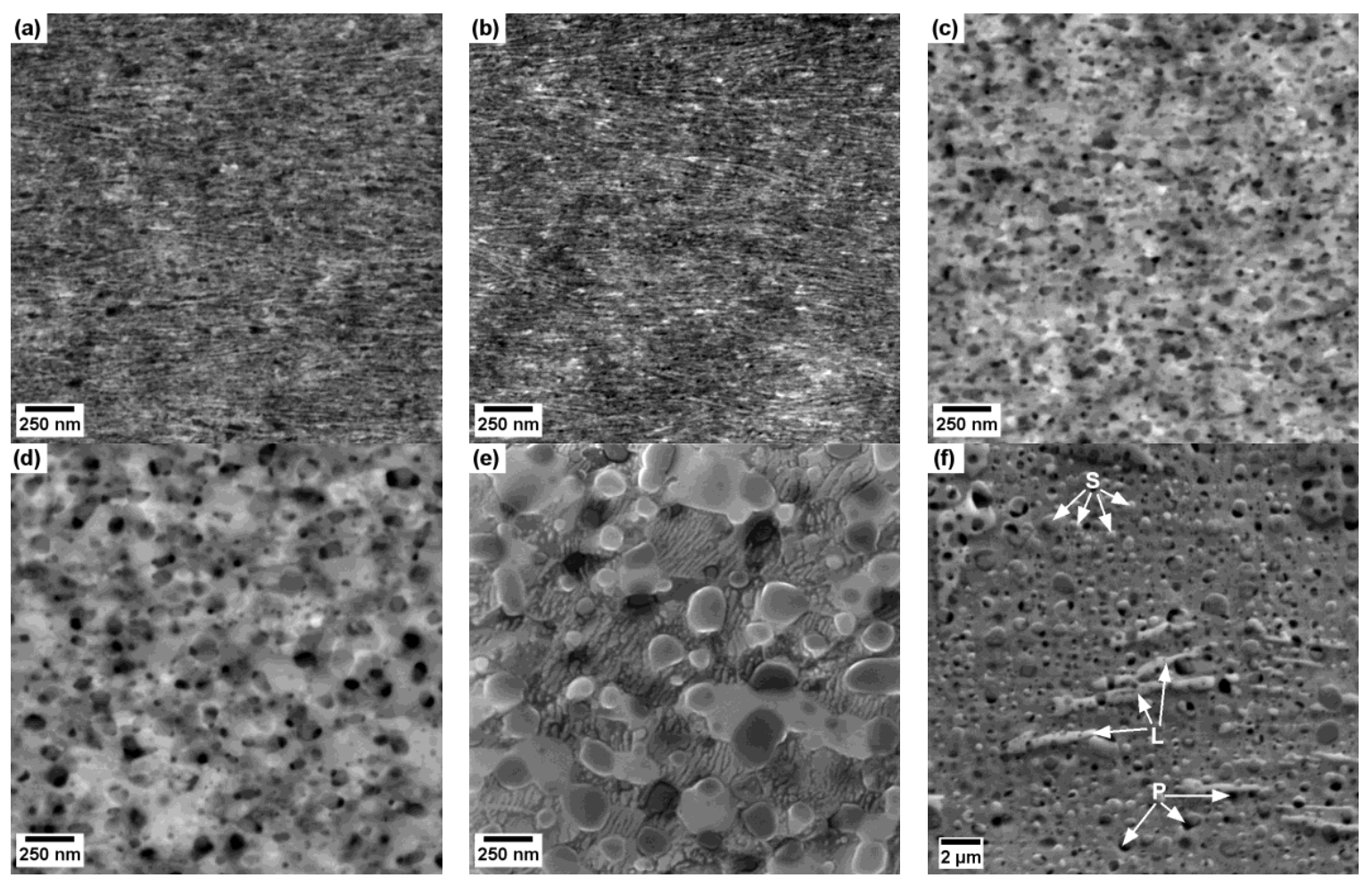

Figure 5. SEM micrographs after isothermal annealing for one hour. (a-d) are recorded with a backscatter-electron detector and show the structural evolution of A50 samples at (a) $200{ }^{\circ} \mathrm{C},(\mathbf{b}) 300{ }^{\circ} \mathrm{C}$, (c) $400{ }^{\circ} \mathrm{C}$, and (d) $500{ }^{\circ} \mathrm{C}$. The lamellar structure observed in B50 samples at $600{ }^{\circ} \mathrm{C}$ is shown in (e). The structure after annealing at $800^{\circ} \mathrm{C}$ is shown in (f) and selected elongated precipitates (L), spherical precipitates $(\mathrm{S})$ and pores $(\mathrm{P})$ are indicated. The growth direction is from left to right for all images.
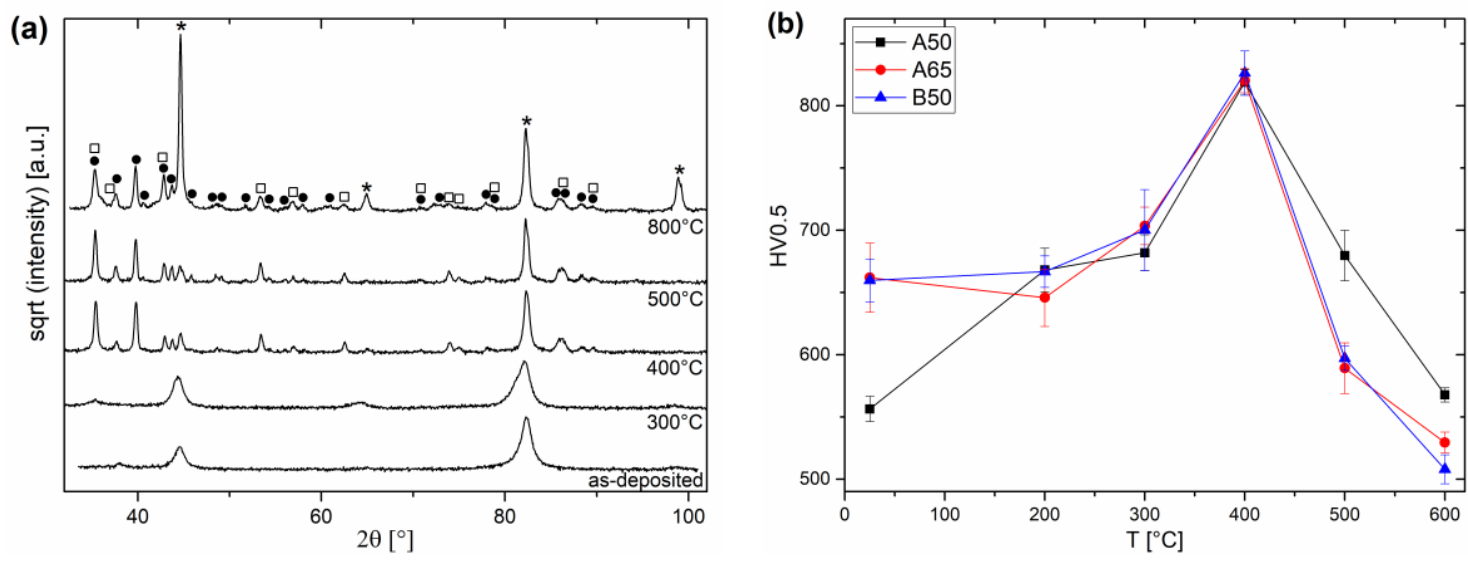

Figure 6. (a) XRD patterns and (b) hardness evolution of isothermally annealed A65 deposits. Bragg peaks of ferrite, cementite, and magnetite are indicated with $*, \bullet$, and $\square$, respectively.

For even higher annealing temperatures, further coarsening takes place accompanied by a decreasing microhardness. A lamellar substructure appears in the matrix after annealing at $600{ }^{\circ} \mathrm{C}$; this effect is particularly pronounced in the B50 samples (Figure 5e). However, no new phases are observed in the XRD patterns even for annealing treatments at $800{ }^{\circ} \mathrm{C}$, i.e., above the eutectoid 
temperature of the Fe-C system [21]. Using SEM and nanoindentation at specific positions, identified by atomic force microscopy with the nanoindenter tip, three features could be identified in the ferritic matrix after annealing at $800{ }^{\circ} \mathrm{C}$ (Figure 5f). First, elongated particles of about $500 \mathrm{~nm}$ in width and several microns in length with a nanoindentation hardness of $16.6 \pm 1.0 \mathrm{GPa}$. Next, approximately spherical precipitates are distributed in both the matrix and the larger elongated particles. They have a large size distribution from tens of nanometers up to about one micron and a nanoindentation hardness of $8.4 \pm 1.4 \mathrm{GPa}$. Finally, pores are identified with similar size and shape as the second type of precipitates. XRD patterns after annealing at $800{ }^{\circ} \mathrm{C}$ still show ferrite, cementite, and magnetite, but the peak width is significantly reduced and the intensity distribution is changed as compared to the lower-annealed samples (Figure 6a).

\section{Discussion}

The results show that Fe-C alloys can be deposited from various citrate-based electrolytes with the newly proposed bath leading to very similar deposits as compared to the bath taken from the literature. In the following, three aspects of the results, namely the carbon and oxygen codeposition, the thermal stability of the deposits, as well as the range of suitable electrolytes for electrodeposition of Fe-C alloys, are discussed in more detail.

\subsection{Codeposition of Carbon and Oxygen}

The codeposition of $1.0 \pm 0.1 \mathrm{wt} \% \mathrm{C}$ for B50 samples corresponds well with the $0.96 \mathrm{wt} \%$ $\mathrm{C}$ that have been reported by Haseeb et al. for the same deposition conditions [8]. The chemical analysis shows that with the new citrate bath (A50 and A65) similar carbon contents are obtained. Also with other baths based on iron citrate complexes, the incorporation of about $1 \mathrm{wt} \% \mathrm{C}$ has been regularly reported in the literature over a large range of current densities [3-6,10,12]. Only if the current density falls below a threshold value of about $-10 \mathrm{~mA} / \mathrm{cm}^{2}$, does the carbon content decrease significantly [4,12]. The mechanism of the codeposition process is still unclear, but it is likely that organic species (based on citrate or ascorbic acid in the bath) are adsorbed at the growth front and incorporated into the metallic matrix [4,12]. In citrate baths at the $\mathrm{pH}$ range of the present study, ferrous ions are mostly bound to complexes $\mathrm{FeCit}^{-}$and FeHCit [22,23]. In the vicinity of the cathode, the concentration of $\mathrm{FeCit}^{-}$might be additionally enhanced due to Coulomb interaction. However, the deposition of metallic iron does not result from the reduction of these species, but from significantly more diluted species $\mathrm{FeOH}^{+}$according to the findings of Danilov et al. [23]. For this reason, it is likely that citrate complexes are accumulated (and adsorbed) at the cathode, where their reduction is impeded and they are trapped by the growing metal leading to the incorporation of carbon. However, no specific experiments to prove this hypothesis have been performed in the present work. The adsorption of organic species impedes the growth of existing crystals during deposition, resulting in an enhanced nucleation rate and a refinement of the microstructure. This explains the nanocrystalline structure of the deposits under investigation in contrast to the coarser deposits observed at low current densities.

Whereas the codeposition of carbon is intended due to its beneficial effect on the mechanical properties, the codeposition of oxygen is expected to result in embrittlement and is generally undesired for this reason. These alloying effects are well-known from steels, in which carbon is regularly used as an alloying element resulting in the industrially important group of carbon steels. On the other hand, the oxygen content is reduced to $50 \mathrm{ppm}$ and less during production in order to improve the quality of the steels [24]. However, the codeposition of oxygen in the electrodeposition of iron, and particularly Fe-C, has regularly been observed $[4,15,25]$ and is also present in the present study. Due to the lack of reasonable results via chemical analysis, the oxygen content was estimated from the amount of magnetite in $800{ }^{\circ} \mathrm{C}$ annealed samples that was determined via Rietveld refinement of the XRD data and then converted to oxygen contents assuming a near-equilibrium state with all dissolved oxygen transformed into magnetite. With this method, the oxygen contents of A50, A65, and B50 samples are estimated to be 5, 4, and $3 \mathrm{wt} \%$. Although these results should be considered 
with care due to the general inaccuracy, the effect of texture and instabilities of the Rietveld refinement process, the carbon contents obtained via this method equal 1.2-1.3 wt \% for all three conditions, which is in good agreement with the $1.1 \pm 0.1 \mathrm{wt} \%$ obtained from chemical analysis and shows the plausibility of the results. Whereas the oxygen contents contradict the negligible oxygen contents up to $-30 \mathrm{~mA} / \mathrm{cm}^{2}$ and $2 \mathrm{wt} \% \mathrm{O}$ for $-70 \mathrm{~mA} / \mathrm{cm}^{2}$ as reported by Izaki et al. [4], they match very well with the $4.7 \mathrm{wt} \%$ obtained by Miyamoto et al. for Fe-C deposits from a chloride bath containing citric and ascorbic acid [15]. The differences can be attributed to the different electrolytes as well as to different experimental conditions such as dissolved oxygen in the electrolytes. Provided there is incorporation of the whole citrate complexes into the deposits as discussed above, this process results in oxygen codeposition, too. However, the incorporation of citrate cannot account for the higher oxygen contents as compared to the carbon content. Thus, we assume that the majority of codeposited oxygen originates from the incorporation of hydroxides. Ferric hydroxides are well-known to precipitate at the $\mathrm{pH}$ of the deposition conditions A50 and A65 and particularly in the vicinity of the cathode due to the enhanced $\mathrm{pH}$ in this region. Since the $\mathrm{pH}$ rise next to the cathode directly correlates with the hydrogen evolution, enhanced hydrogen evolution is supposed to result in enhanced oxygen codeposition from ferric hydroxides. Furthermore, $\mathrm{FeOH}$ has been discussed as an intermediate species of iron deposition from citrate baths [23] and might be incorporated, too. Oxygen contents have been reported to be reduced by inert gas bubbling and by adding boric acid to the bath [25]. However, gas bubbling also causes bath agitation, which is known to reduce the current efficiency for Fe-C deposition [10]. In this study, the use of citrate buffer solutions as a potential alternative to boric acid was tested. However, no significant reduction of the oxygen content according to the XRD analysis was obtained, but the current efficiency was reduced as compared to the conditions A50, A65, and B50. Another promising way to avoid oxygen codeposition is electrodeposition from non-aqueous baths. Although nanocrystalline, oxygen-free iron deposits have recently been obtained with this method [26], the low current densities impede the preparation of quasi-bulk material as intended in the present work.

As shown in Figure 3, the as-deposited state consists practically of a single-phase solid solution of iron, carbon, and oxygen. The measured carbon and estimated oxygen contents are far beyond the negligible equilibrium solubilities of these elements in iron at room temperature [21,27]. This strong supersaturation raises the question of how the carbon and oxygen atoms are distributed in the ferritic structure. If the supersaturation was achieved via a homogeneous distribution in the interstitial sites of the ferritic lattice, the lattice parameter would be significantly increased which is in contradiction to the XRD results. For this reason, it is more likely that carbon and oxygen are concentrated at defects sites, in particular at the grain boundaries. The incorporation of carbon and oxygen from adsorbed species at the growth front during deposition might explain such a distribution since the adsorbed species impede the grain growth, give rise to the formation of new grains, and are then incorporated at the newly formed grain boundaries. The formation of clustered carbon distributions rather than a homogeneous distribution of interstitial carbon atoms has also been proposed by Haseeb et al. based on Mössbauer spectroscopy measurements [8]. The segregations result in a mechanical weakening of the grain boundaries. This explains the intercrystalline fracture in the bending tests and the catastrophic failure and transformation into powder under compressive loading. The large scatter of the load bearing capacity in these tests is caused by the statistical distribution of defects since the size of the largest defect differs from one sample to another and immediately affects the maximum applied load before failure. The elongated, straight grain boundaries in the growth direction facilitate crack growth which results in the low maximum stresses in the bending tests as well as the preferred crack formation in this direction during Vickers indentation.

The hardness of the as-deposited samples in the current study is within the range of 600-800 HV that can be found in the literature $[4,6-8,12,15]$. The hardness of the B50 samples in this study is lower than the $810 \mathrm{HV}$ reported for the same deposition conditions by Haseeb et al. [8]. Although the microstructure and the carbon contents look almost identical, this difference as well as the different hardness values in the literature might be a result of different experimental conditions leading to 
structural differences of the deposits, e.g., concerning oxygen contents and residual stresses. However, the different loads used in these studies (e.g., $20 \mathrm{~g}$ in [8] vs. $500 \mathrm{~g}$ in the present work) might also contribute to the hardness differences via the indentation size effect [28]. The lower hardness of the A50 samples as compared to the A65 and B50 structures in the present work is probably caused by the higher oxygen contents in this case which facilitate crack growth and, thus, penetration by the indenter. Strengthening via oxide formation or oxygen redistribution might explain the outbalancing of this hardness difference upon annealing.

\subsection{Discussion of the Thermal Stability}

In contrast to the disastrous effect of the grain boundary segregations on the mechanical properties, they provide the fundament for a strong thermal stability. In the temperature range up to $300{ }^{\circ} \mathrm{C}$, where the carbon and oxygen atoms stay in segregated solid solution, they inhibit any significant grain growth in spite of the very small grain size of about $20 \mathrm{~nm}$. The slight hardness increase for these moderate annealing temperatures might be caused by grain boundary relaxation strengthening [29]. However, grain boundary relaxation does not provide significant strengthening upon annealing in the present case because the high diffusivity of carbon and oxygen enables their relocalization, i.e., a relaxation of the segregated grain boundary structure, already at room temperature.

The precipitation of cementite and magnetite, that is observed for higher temperatures in the present study, is in contradiction to the formation of cementite via intermediate carbides as found by Izaki et al. [5] and Haseeb et al. [7,8]. However, the preservation of the same peak positions in the XRD patterns even after austenitization at $800{ }^{\circ} \mathrm{C}$ clearly shows that the observed phase is the thermodynamically stable magnetite and no intermediate carbide. Furthermore, the qualitative evidence of oxygen codeposition via X-ray photoelectron spectroscopy and the negligible solubility of oxygen in iron according to the phase diagram require the formation of an oxide phase during annealing. The two precipitate phases can also be differentiated by nano-indentation and according to their shape and size after annealing at $800{ }^{\circ} \mathrm{C}$. On the contrary, only approximately spherical precipitates of nanometer to sub-micron size exist at lower annealing temperatures in spite of very similar XRD patterns, indicating a similar morphology of magnetite and cementite in this temperature range. This difference of the $800^{\circ} \mathrm{C}$ samples as compared to the lower annealing temperatures can be attributed to passing the eutectoid temperature of the Fe-C phase diagram $\left(740{ }^{\circ} \mathrm{C}[21]\right)$. Thus, the ferritic matrix transforms into austenite, in which carbon has a solubility of nearly $1 \mathrm{wt} \%$ at $800{ }^{\circ} \mathrm{C}$ [21]. The spherical cementite particles dissolve during annealing and precipitate again during cooling, giving rise to a change of particle shape and size with a large size enabled by the low cooling rate in the vacuum furnace. On the contrary, oxygen does not show any considerable solubility in iron up to $1528^{\circ} \mathrm{C}$, where the melting process sets in [27]. For this reason, the oxide particles may change their size via diffusion and may transform from magnetite to wüstite during heating and transform back during cooling, but no complete dissolution and re-nucleation takes place. Thus, the large elongated precipitates in Figure $5 \mathrm{f}$ can be identified as cementite, whereas the smaller spherical precipitates can be ascribed to magnetite.

The precipitation affects the hardness of the deposits in two ways. On the one hand, the formation of second-phase particles with a significantly higher hardness compared to the matrix results in a hardening. On the other hand, the vanishing grain boundary segregations facilitate grain growth in the matrix, causing a hardness decrease. At $400^{\circ} \mathrm{C}$, the nanoprecipitates provide a strengthening effect and the elongated grains in the matrix are preserved, indicating that the precipitation is not yet completed and grain boundary segregations still stabilize the nanocrystalline structure. This explains the hardening effect at this temperature (Figure 6b), which has been observed in a similar temperature range by Izaki et al. [5]. At higher temperatures, the loss of the grain boundary stabilization due to complete precipitation of carbon and oxygen in the form of cementite and magnetite gives rise to grain growth, causing the observed softening. The growth of the precipitates with increasing temperature supports this coarsening, since the number of obstacles for grain boundary motion 
decreases. Nevertheless, it is worth mentioning that the grain size after annealing at $600{ }^{\circ} \mathrm{C}$ is still below one micron, which can be attributed to the barrier to grain growth promoted by the large fraction of second-phase particles. The higher hardness of the A50 deposits at this high annealing temperature as compared to the A65 and B50 deposits (Figure 6b) is attributed to a larger amount of oxide precipitates due to the higher oxygen content. The lamellar structure observed at $600{ }^{\circ} \mathrm{C}$ supports the thermal stability because of its nanocrystalline structure. However, its formation is currently not understood. Its random orientation excludes direct formation of a two-phase lamellar structure from the lamellar single-phase structure with grain boundary segregations in the as-deposited state. The structure looks like the result of a eutectoid decomposition, but the annealing temperature is well below the eutectoid temperature of the Fe-C system.

\subsection{Comparison of Different Electrolytes for Fe-C Electrodeposition}

The results show no significant differences between the samples obtained from the deposition conditions A50, A65, and B50. The existence of a range of deposition conditions, particularly current densities, in which deposits with only small deviations in carbon content, microstructure, and, thus, hardness are obtained, can also been concluded from former studies such as [11]. The new citrate bath tested in this study is within this range.

Citrate buffer solutions were tested in this study in order to impede the $\mathrm{pH}$ increase next to the substrate due to the evolution of hydrogen. The layers from these baths also had a similar structure and hardness between those of A50 and A65 deposits. However, the current efficiency was significantly reduced. Thus, this approach is not suitable for the electrodeposition of thick Fe-C films.

The enhanced hardness of electrodeposits from succinic acid baths has been reported by Fujiwara et al. [11]. This was reproduced in preliminary experiments of the current work resulting in a hardness of about $750 \mathrm{HV}$ in the as-deposited state. However, low bath stability and enhanced brittleness of the deposits limit the practical use of the succinic acid bath.

The citrate bath from this study was found to be the most suitable electrolyte for the deposition of thick films with high hardness. The deposition under conditions A65 allows the preparation of films with almost identical structure and properties compared to B50, but with higher current density, i.e., faster growth rate. The higher deposition temperature increases the diffusivity of the species in the electrolyte, allowing the use of higher current densities. The temperature increase does not result in coarsening of the structure due to its thermal stability. The slightly larger $\mathrm{pH}$ increase for A65 as compared to A50 is not a consequence of the increased temperature, but rather of the larger passing charge due to the higher current density over the same deposition time. The $\mathrm{pH}$ change is significantly smaller than for B50, making A65 the most promising deposition conditions for the preparation of quasi-bulk Fe-C films. Nevertheless, the practical use of the deposits is limited due to the codeposition of oxygen causing embrittlement of the structure.

\section{Conclusions}

The codeposition of carbon in iron electrodeposits from iron-citrate complexes in the electrolyte was reviewed and a new bath based on sodium citrate proposed which was found to be suitable for the deposition of thick films up to more than $800 \mu \mathrm{m}$. The nanocrystalline structure with a grain size of about $20 \mathrm{~nm}$ results in a hardness of up to $660 \mathrm{HV}$. This hardness can be further increased to more than $800 \mathrm{HV}$ via annealing. However, the embrittlement due to the codeposition of oxygen limits the mechanical load-bearing capacity of the deposits from both the new and previously proposed electrolyte. On the other hand, the codeposited carbon and oxygen provide considerable thermal stability of the structure. Even after annealing at $600^{\circ} \mathrm{C}$, the structure is still ultrafine-grained.

Author Contributions: T.M., A.B., and R.P. conceived and designed the experiments. T.M. performed the electrodeposition experiments and wrote the manuscript. T.M. and J.G. performed the structural and mechanical analysis of the deposits. All authors contributed to the finalization of the manuscript. 
Funding: Funding of this work has been provided by the European Research Council under ERC Grant Agreement No. 340185 USMS.

Acknowledgments: Parts of this research were carried out at PETRA III at DESY, a member of the Helmholtz Association (HGF). The authors would like to thank Pradipta Ghosh and Torben Fischer for assistance in using the P07 HEMS beamline.

Conflicts of Interest: The authors declare no conflict of interest. The founding sponsors had no role in the design of the study; in the collection, analyses, or interpretation of data; in the writing of the manuscript, and in the decision to publish the results.

\section{References}

1. Petrov, Y.N. Porous Electrodeposition of Iron and its Use in Repair of Machine Parts. Dokl. Akad. Nauk Tadzhikskoi SSR 1957, 20, 67-70. (In Russian)

2. Izaki, M.; Enomoto, H.; Omi, T. Hardness and Carbon Content of Fe Electroplate from Sulfate Bath Containing 1-Ascorbic Acid and Citric Acid. J. Surf. Finish. Soc. Jpn. 1989, 40, 1304-1305. (In Japanese) [CrossRef]

3. Izaki, M.; Enomoto, H.; Omi, T. Structure and Hardness of Fe-C Alloy Film Electrodeposited from an Iron Sulfate Electrolyte. J. Jpn. Inst. Met. Mater. 1992, 56, 636-640. (In Japanese) [CrossRef]

4. Izaki, M.; Omi, T. Structural Characterization of Martensitic Iron-Carbon Alloy Films Electrodeposited from an Iron(II) Sulfate Solution. Metall. Mater. Trans. A 1996, 27, 483-486. [CrossRef]

5. Izaki, M.; Enomoto, H.; Nakae, A.; Terada, S.; Yamauchi, E.; Omi, T. Phase Transformations and Hardness Changes in Electrodeposited Fe-C Alloy Films. J. Surf. Finish. Soc. Jpn. 1994, 45, 1302-1307. (In Japanese) [CrossRef]

6. Haseeb, A.S.M.A.; Huq, M.Z. Electrodeposition of Martensitic Iron-Carbon Alloy Coatings at Room Temperature. Met. Finish. 1997, 95, 30-34. [CrossRef]

7. Haseeb, A.S.M.A.; Arita, M.; Hayashi, Y. Thermal Decomposition Study of Electrodeposited Fe-C and Fe-Ni-C Alloys by Differential Scanning Calorimetry. J. Mater. Sci. 2001, 36, 4739-4743. [CrossRef]

8. Haseeb, A.S.M.A.; Hayashi, Y.; Masuda, M.; Arita, M. On the Nature of the Electrochemically Synthesized Hard Fe-0.96 Mass Pct C Alloy Film. Metall. Mater. Trans. B 2002, 33B, 921-927. [CrossRef]

9. Oh, Y.J.; Ha, H.P.; Byun, J.S. Effect of Pulse Plating on the Hardness and Ductility of Electroplated Fe-C. J. Korean Inst. Surf. Eng. 2002, 35, 141-148. (In Korean)

10. Fujiwara, Y.; Izaki, M.; Enomoto, H.; Nakae, A. Effects of Hydroxycarboxylic Acids on the Electrodeposition of Fe-C Alloys. Denki Kagaku 1993, 61, 840-842.

11. Fujiwara, Y.; Nagayama, T.; Nakae, A.; Izaki, M.; Enomoto, H.; Yamauchi, E. Electrodeposition of Fe-C Alloys from Baths Containing Dicarboxylic Acids with a Linear Alkyl Chain. J. Electrochem. Soc. 1996, 143, 2584-2590. [CrossRef]

12. Fujiwara, Y.; Izaki, M.; Enomoto, H.; Nagayama, T.; Yamauchi, E.; Nakae, A. Optimization of bath composition for hard Fe-C alloy plating. J. Appl. Electrochem. 1998, 28, 855-862. [CrossRef]

13. Miyamoto, N.; Sakamoto, S.; Tamuro, H.; Matsuoka, M.; Tamaki, J. Effect of Carbon Content on Structural and Mechanical Properties of Fe-Co-C Alloy Electrodeposited from Aqueous Solutions. J. Electrochem. Soc. 2005, 152, C488-C492. [CrossRef]

14. Izaki, M.; Miyamoto, N.; Nakae, A.; Hasegawa, T.; Watase, S.; Chigane, M.; Fujiwara, Y.; Ishikawa, M.; Enomoto, H. Martensitic Iron-Carbon-Boron Alloy Electrodeposit with Improved Mechanical Properties. J. Electrochem. Soc. 2002, 149, C370-C374. [CrossRef]

15. Miyamoto, N.; Yoshida, K.; Matsuoka, M.; Tamaki, J. Effect of Phosphorus Content on Mechanical Properties of Electrodeposited Fe-C-P Alloys. J. Electrochem. Soc. 2004, 151, C645-C648. [CrossRef]

16. Gamburg, Y.D.; Zangari, G. Theory and Practice of Metal. Electrodeposition; Springer: New York, NY, USA, 2011; p. 302.

17. Fukumuro, N.; Kojima, S.; Fujino, M.; Mizuta, Y.; Maruo, T.; Yae, S.; Fukai, Y. Hydrogen-Induced Superabudant Vacancies in Electrodeposited Fe-C Alloy Films. J. Alloys Compd. 2015, 645, S404-S407. [CrossRef]

18. Zabinski, P.R.; Meguro, S.; Asami, K.; Hashimoto, K. Electrodeposited Co-Fe and Co-Fe-C Alloys for Hydrogen Evolution in a Hot $8 \mathrm{kmol} \mathrm{m}^{-3} \mathrm{NaOH}$ Solution. Mater. Trans. 2003, 44, 2350-2355. [CrossRef]

19. Schell, N.; King, A.; Beckmann, F.; Fischer, T.; Müller, M.; Schreyer, A. The High Energy Materials Science Beamline (HEMS) at PETRA III. Mater. Sci. Forum 2014, 772, 57-61. [CrossRef] 
20. Niihara, K. A Fracture Mechanics Analysis of Indentation-Induced Palmqvist Cracks in Ceramics. J. Mater. Sci. Lett. 1983, 2, 221-223. [CrossRef]

21. Okamoto, H. The C-Fe (Carbon-Iron) System. J. Phase Equilib. 1992, 13, 543-565. [CrossRef]

22. Hamm, R.E.; Shull, C.M.; Grant, D.M. Citrate Complexes with Iron(II) and Iron(III). J. Am. Chem. Soc. 1954, 76, 2111-2114. [CrossRef]

23. Danilov, F.I.; Protsenko, V.S.; Ubiikon, A.V. Kinetic Regularities Governing the Reaction of Electrodeposition of Iron from Solutions of Citrate Complexes of Iron(III). Russ. J. Electrochem. 2005, 41, 1282-1289. [CrossRef]

24. Zhang, L.; Thomas, B.G.; Wang, X.; Cai, K. Evaluation and Control of Steel Cleanliness-Review. In Proceedings of the 85th Steelmaking Conference, Nashville, TN, USA, 10-13 March 2002; Volume 85, pp. 431-452.

25. Gadad, S.; Harris, T.M. Oxygen Incorporation during the Electrodeposition of Ni, Fe and Ni-Fe Alloys. J. Electrochem. Soc. 1998, 145, 3699-3703. [CrossRef]

26. Panzeri, G.; Accogli, A.; Gibertini, E.; Rinaldi, C.; Nobili, L.; Magagnin, L. Electrodeposition of high-purity nanostructured iron films from $\mathrm{Fe}(\mathrm{II})$ and $\mathrm{Fe}(\mathrm{III})$ non-aqueous solutions based on ethylene glycol. Electrochem. Acta 2018, 271, 576-581. [CrossRef]

27. Sundman, B. An Assessment of the Fe-O System. J. Phase Equilib. 1991, 12, 127-140. [CrossRef]

28. Nix, W.D.; Gao, H. Indentation size effects in crystalline materials: A law for strain gradient plasticity. J. Mech. Phys. Solids 1998, 46, 411-425. [CrossRef]

29. Hu, J.; Shi, Y.N.; Sauvage, X.; Sha, G.; Lu, K. Grain boundary stability governs hardening and softening in extremely fine nanograined metals. Science 2017, 355, 1292-1296. [CrossRef] [PubMed]

(C) 2018 by the authors. Licensee MDPI, Basel, Switzerland. This article is an open access article distributed under the terms and conditions of the Creative Commons Attribution (CC BY) license (http:// creativecommons.org/licenses/by/4.0/). 